\section{RMD Open}

Rheumatic \&

Musculoskeletal Diseases

\title{
Relationship between clinical and
} patient-reported outcomes in a phase 3 trial of tofacitinib or MTX in MTX-naive patients with rheumatoid arthritis

\author{
Roy Fleischmann, ${ }^{1}$ Vibeke Strand, ${ }^{2}$ Bethanie Wilkinson, ${ }^{3}$ Kenneth Kwok, ${ }^{4}$ \\ Eustratios Bananis ${ }^{5}$
}

To cite: Fleischmann $\mathrm{R}$, Strand V, Wilkinson B, et al. Relationship between clinical and patient-reported outcomes in a phase 3 trial of tofacitinib or MTX in MTXnaïve patients with rheumatoid arthritis. $R M D$ Open 2016;2:e000232. doi:10.1136/rmdopen-2015000232

- Prepublication history and additional material is available. To view please visit the journal (http://dx.doi.org/ 10.1136/rmdopen-2015000232)

RF and VS contributed equally.

Received 16 December 2015 Revised 12 February 2016 Accepted 20 February 2016

CrossMark

For numbered affiliations see end of article.

Correspondence to Dr Eustratios Bananis; stratis.bananis@pfizer.com

\section{ABSTRACT}

Objective: To compare the relationship between clinical measures and patient-reported outcomes (PROs) in patients with rheumatoid arthritis (RA) treated with tofacitinib or methotrexate (MTX). Methods: In a phase 3 randomised controlled trial, patients $(\mathrm{N}=956)$ who were MTX-naive or had received $\leq 3$ doses were randomised and received tofacitinib 5 or $10 \mathrm{mg}$ twice daily or MTX titrated to $20 \mathrm{mg} /$ week. Outcomes included: per cent of patients achieving American College of Rheumatology 70\% responses (ACR70), ACR50, low disease activity (LDA) by Simplified Disease Activity Index (SDAI $\leq 11$ ) and Clinical Disease Activity Index (CDAl $\leq 10)$, remission by SDAI $(\leq 3.3)$ and CDAl ( $\leq 2.8)$, patient-reported Health Assessment Questionnaire-Disability Index (HAQ-DI scores <0.5), pain and global assessment of disease activity.

Results: At month 6, most patients who achieved LDA/remission by one definition achieved LDA/ remission with others; however, discordance between measures was greater with MTX than with tofacitinib. As expected, concordance between CDAI and SDAI responses was high. Overall, patients achieving LDA or ACR50 responses reported less improvement in PROs (HAQ-DI, pain and patient global assessment) compared with clinical measures (tender and swollen joint counts).

Conclusions: Variability in levels of responses between clinical outcomes and PROs should be considered when setting treat-to-target goals in patients with RA.

Trial registration number: NCT01039688; Postresults.

\section{INTRODUCTION}

In the phase 3 ORAL Start randomised controlled trial (RCT), treatment with tofacitinib 5 or $10 \mathrm{mg}$ twice daily as monotherapy resulted in significant reductions in signs and symptoms of rheumatoid arthritis (RA), inhibition of progression of structural

\section{Key messages}

What is already known about this subject?

- The role of patient-reported outcomes in assessing the efficacy of treatments for rheumatoid arthritis is complementary to that of clinical outcomes, as clinical measures may not reflect patient expectations of treatment.

What does this study add?

- This study compared the relationship between validated clinical responses and patient-reported outcomes in a randomised controlled trial in methotrexate-naïve patients with rheumatoid arthritis receiving tofacitinib or methotrexate.

- Variability was observed between clinical responses and patient-reported outcomes.

How might this impact on clinical practice?

- In addition to clinical responses, patient-perceived benefits of therapy should be considered when setting treat-to-target goals in rheumatoid arthritis.

damage, compared with methotrexate (MTX), and improvements in physical functioning and health-related quality of life (HRQoL). ${ }^{1}$

Clinical and patient-reported outcomes (PROs) have complementary roles in determining the efficacy of RA treatments. ${ }^{2}{ }^{3}$ At the individual patient level, there are those who respond by one clinical definition but not by another. ${ }^{4}$ Importantly, clinical measures may not necessarily match patient expectations of treatment benefit, especially when initiating new treatment. ${ }^{5}$ It is therefore important to understand the association between improvements in validated clinical response criteria and PROs to better inform therapeutic decisions.

We compare the relationship between validated clinical responses and PROs in patients 
with RA who were MTX-naïve (or had received $\leq 3$ doses), receiving tofacitinib or MTX in the ORAL Start RCT.

\section{METHODS}

Trial design and patients

ORAL Start (NCT01039688; Pfizer protocol A3921069) was a 24-month, phase 3 RCT conducted in 151 centres worldwide; details and primary results have been reported previously. ${ }^{1}$ Eligible patients were $\geq 18$ years old with active RA by American College of Rheumatology (ACR) 1987 Revised Criteria, ${ }^{6}$ with $\geq 3$ distinct joint erosions on hand/wrist or foot radiographs, and/or positive IgM rheumatoid factor $(\mathrm{RF}+)$ or anti-cyclic citrullinated peptide (anti-CCP+).

Patients were randomised (2:2:1) to receive tofacitinib 5 or $10 \mathrm{mg}$ twice daily, or MTX starting at $10 \mathrm{mg} /$ week with $5 \mathrm{mg}$ /week increases every month to $20 \mathrm{mg}$ /week, if tolerated, each administered as monotherapy. After publication of ORAL Start, one of the study sites, which randomised eight patients, was found to be noncompliant to study procedures and those patients were removed from the efficacy analyses presented here.

The trial was approved by Institutional Review Boards (IRBs) and/or Independent Ethics Committees at each investigational centre or a central IRB and conducted in accordance with the Declaration of Helsinki and International Conference on Harmonisation Good Clinical Practice Guidelines. All patients provided written informed consent.

\section{Outcome measures}

The primary outcome measures of this study were reported previously. ${ }^{1}$ Clinical measures included ACR50 and ACR70 responses, low disease activity (LDA) by Simplified Disease Activity Index (SDAI $\leq 11)$ and Clinical Disease Activity Index $(\mathrm{CDAI} \leq 10)$, remission by SDAI $(\leq 3.3)$ and CDAI $(\leq 2.8)$ at month 6 , and patientreported Health Assessment Questionnaire-Disability Index (HAQ-DI), pain (by visual analogue scale) and patient global assessment of disease activity (PtGA) as components of the ACR response criteria. Patients reporting improvements in HAQ-DI that achieved a value of $<0.5$ (eg, <normative values of 0.5 ; 0 or 1 scores indicating none or mild physical impairment, respectively) at month 6 were considered HAQ-DI 'responders'.

For pairs of the above outcome measures, the percentages of patients who responded by both outcome measures was determined: for example, (1) ACR50 responders who also achieved SDAI LDA and (2) ACR70 responders who also achieved CDAI remission.

Mean percentage improvements from baseline in PROs, tender (TJC) and swollen joint counts (SJC), and physician global assessment (PGA) of disease activity at month 6 were determined among responders by: ACR50, ACR70, CDAI LDA, CDAI and SDAI remission, or HAQ-DI $<0.5$.

\section{Statistical analysis}

Data are reported for all randomised patients with $\geq 1$ dose of study medication and $\geq 1$ postbaseline measurement. General trends in the percentages of patients achieving defined clinical and PRO improvements ('response rates') are described. Venn diagrams are used to demonstrate high concordance versus discordance between different clinical measures. No imputations for missing data were performed; only patients with non-missing values for both measures were included in these analyses.

\section{RESULTS}

\section{Patients}

Of the 958 patients randomised, 956 were treated (2 patients were randomised but not treated): tofacitinib $5 \mathrm{mg}, \mathrm{n}=373,10 \mathrm{mg}, \mathrm{n}=397$, or MTX, $\mathrm{n}=186$. Patient demographics and baseline characteristics were similar across active treatment groups: mean age 48.8-50.3 years, females: $77-82 \%$, mean disease duration 2.7-3.4 years, and median disease duration $0.7-0.8$ years. ${ }^{1}$

\section{Clinical outcomes and comparisons with PROs, TJC, SJC and PGA}

At month 6, greater proportions of patients achieved ACR50 and ACR70 responses, as well as CDAI and SDAI LDA and remission with tofacitinib 5 or $10 \mathrm{mg}$ than with MTX (figure 1).

Regardless of treatment group, most patients who were ACR50 responders, in LDA by SDAI or CDAI, or reported HAQ-DI $<0.5$, also responded to at least one of the other definitions (table 1). However, approximately one-third of patients with ACR50 and SDAI/CDAI LDA responses did not report HAQ-DI scores $<0.5$ : $29 \%$ and $37 \% / 35 \%$ in tofacitinib $5 \mathrm{mg}$ and $30 \%$ and $29 \% / 28 \%$ in $10 \mathrm{mg}$ groups; the proportion of patients who did not report HAQ-DI scores $<0.5$ was numerically greater with MTX: 50\% ACR50 and 51\%/48\% SDAI/CDAI LDA (table 1). Across treatment groups, most patients (71-94\%) who achieved SDAI or CDAI remission were ACR70 responders; conversely, only $38-51 \%$ of ACR70 responders also achieved SDAI or CDAI remission (table 1). Across treatment groups, most patients who achieved ACR70, SDAI or CDAI remission also reported HAQ-DI scores $<0.5$ (tofacitinib $5 \mathrm{mg}, 84-88 \%$; tofacitinib $10 \mathrm{mg}, 78-84 \%$; MTX, 70-73\%; table 1).

Patients receiving MTX reported less overall improvement in PROs compared with tofacitinib 5 or $10 \mathrm{mg}$, particularly those who achieved CDAI LDA or reported HAQ-DI scores $<0.5$ (figure 2). Mean percentage improvements from baseline in PtGA $(66 \%, 67 \%$ and $64 \%$ with MTX, tofacitinib $5 \mathrm{mg}$ and $10 \mathrm{mg}$, respectively) and pain (75\%, $70 \%$ and $70 \%$, respectively) reported by ACR50 responders were more consistent and larger than by responders defined by CDAI LDA (PtGA: $43 \%, 57 \%$ and $62 \%$; pain: $45 \%, 53 \%$ and $69 \%$ with MTX, tofacitinib $5 \mathrm{mg}$ and $10 \mathrm{mg}$, respectively) and HAQ-DI $<0.5$ (PtGA: 42\%, $63 \%$ and $59 \%$; pain: $49 \%, 62 \%$ and $68 \%$, respectively; 
Figure 1 Percentage of responders at month 6 by (A) ACR50, SDAI/CDAI LDA, and HAQ-DI <0.5 and (B) ACR70, SDAI/CDAI REM, and $\mathrm{HAQ}$-DI <0.5. ACR, American College of Rheumatology; BID, twice daily; CDAI, Clinical Disease Activity Index; HAQ-DI, Health Assessment Questionnaire-Disability Index; LDA, low disease activity; MTX, methotrexate; N, number of patients in analysis; REM, remission; SDAI, Simplified Disease Activity Index.
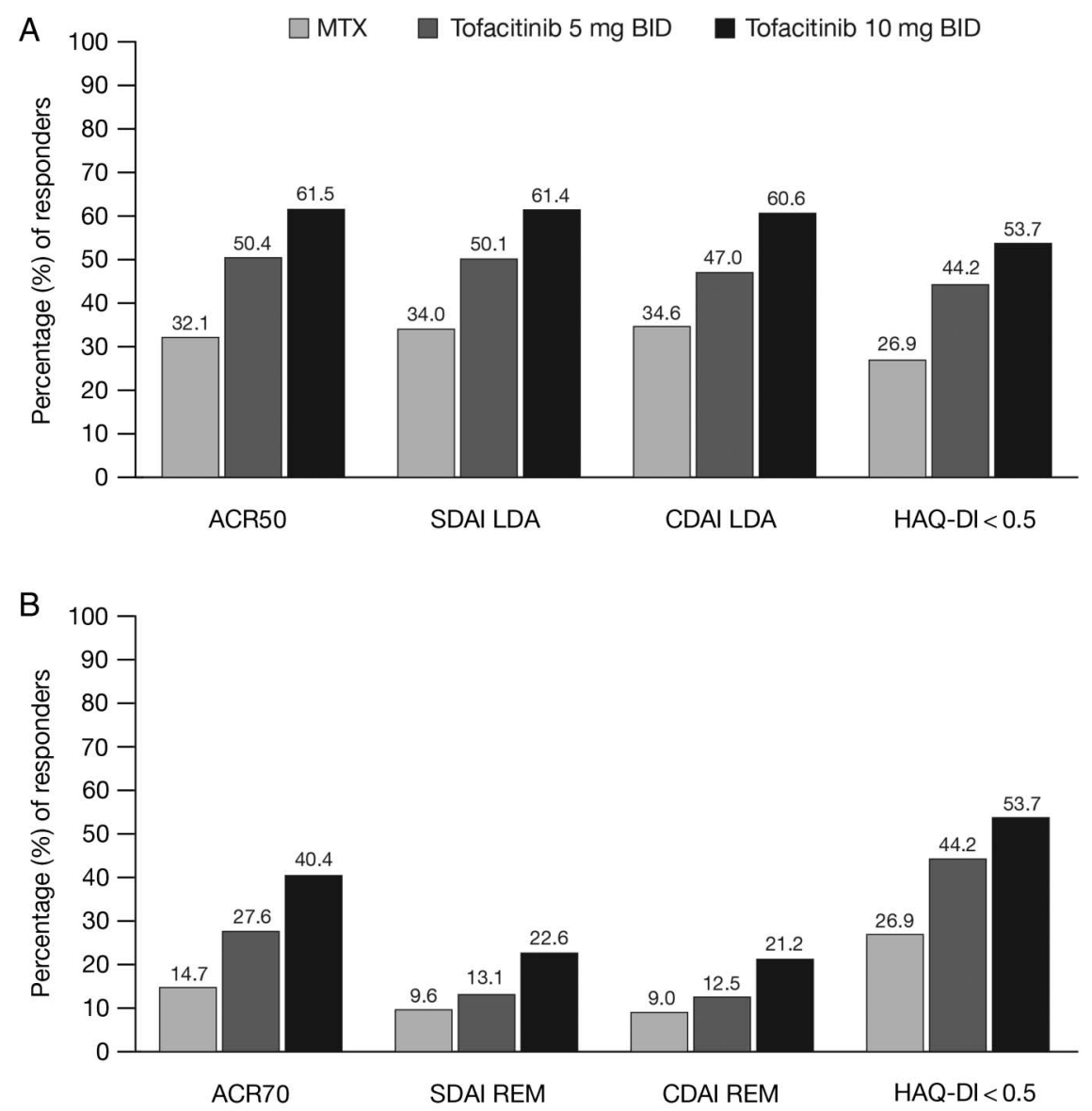

$\begin{array}{lcccc}\text { MTX, N } & 156 & 156 & 156 & 156 \\ \text { Tofacitinib } & 337 & 335 & 336 & 337 \\ \begin{array}{l}5 \text { mg BID, N } \\ \text { Tofacitinib }\end{array} & 364 & 363 & 363 & 363 \\ 10 \text { mg BID, N } & 363 & & \end{array}$

figure 2). Improvement in HAQ-DI scores (decrease from baseline) at month 6 was greatest in patients who reported HAQ-DI $<0.5(77 \%, 88 \%$ and $89 \%$ with MTX, tofacitinib $5 \mathrm{mg}$ and $10 \mathrm{mg}$, respectively), and slightly numerically greater in ACR50 responders $(68 \%, 78 \%$ and $79 \%$, respectively) than in patients with CDAI LDA (60\%, 70\% and $78 \%$, respectively; figure 2). As expected, improvements in patients with SDAI LDA were similar to those with CDAI LDA (data not shown). Patients achieving responses by ACR70, CDAI and SDAI remission reported similar percentage improvements from baseline in PtGA and pain; outcomes were similar between MTX and tofacitinib treatment groups. Among ACR70 responders or those achieving CDAI or SDAI remission, mean percentage improvements in PtGA: 81-82\% (MTX), $75-77 \%$ (tofacitinib $5 \mathrm{mg}$ ), and $67-72 \%$ (tofacitinib $10 \mathrm{mg}$ ) were reported; and similarly in pain scores: $82-86 \%, 77-79 \%$, and $76-85 \%$, respectively (figure 3). Overall, patients achieving clinical responses reported less improvement from baseline in pain and PtGA compared with TJC, SJC,
PGA and HAQ-DI, most prominently in patients with HAQ-DI $<0.5$ and CDAI LDA (figures 2 and 3 ).

\section{Concordance/discordance of outcomes}

Venn diagrams presented in figure 4 display the degree of concordance between clinical outcomes in tofacitinib $5 \mathrm{mg}$ and MTX treatment groups. In total, 55-62\% of patients who achieved CDAI LDA or ACR50 responses were responders by both definitions (figure 4A). Concordance between CDAI remission and ACR70 responses was lower (36-37\%) as more patients achieved an ACR70 response than CDAI remission (28\% vs $13 \%$, with tofacitinib $5 \mathrm{mg}$ and $15 \%$ vs $9 \%$ with MTX; figure 4B). Among ACR50 or HAQ-DI responders receiving tofacitinib $5 \mathrm{mg}, 60 \%$ achieved both outcomes; among MTX-treated patients, even fewer (37\% of HAQ-DI or ACR50 responders) achieved both (figure 4C). Concordance between ACR70 and HAQ-DI responses was even lower as there were more HAQ-DI $<0.5$ responders versus ACR70 responders, but was nonetheless higher with tofacitinib $5 \mathrm{mg}$ 
Table 1 ACR50, LDA, ACR70 and remission clinical disease outcomes at month 6 (percentage of patients achieving a response who were also responders by the first outcome)

\begin{tabular}{|c|c|c|c|c|c|}
\hline \multicolumn{6}{|c|}{ ACR50 and LDA clinical disease activity outcomes at month 6} \\
\hline & & ACR50 & SDAI LDA & CDAI LDA & HAQ-DI (<0.5) \\
\hline \multirow[t]{3}{*}{ Overall responders, $n / \mathrm{N}(\%)$} & Tofacitinib 5 mg BID & $170 / 337(50.4)$ & $168 / 335(50.1)$ & $158 / 336(47.0)$ & $149 / 337(44.2)$ \\
\hline & Tofacitinib $10 \mathrm{mg}$ BID & 224/364 (61.5) & 223/363 (61.4) & $220 / 363(60.6)$ & 195/363 (53.7) \\
\hline & MTX & $\begin{array}{l}50 / 156(32.1) \\
\text { 2nd Outcome }\end{array}$ & $53 / 156(34.0)$ & $54 / 156(34.6)$ & $42 / 156(26.9)$ \\
\hline 1st Outcome & Treatment & $\begin{array}{l}\text { ACR50 } \\
\text { responder }\end{array}$ & $\begin{array}{l}\text { SDAI LDA } \\
(\leq 11)\end{array}$ & $\begin{array}{l}\text { CDAI LDA } \\
(\leq 10)\end{array}$ & $\begin{array}{l}\text { HAQ-DI } \\
(<0.5)\end{array}$ \\
\hline \multirow[t]{3}{*}{ ACR50 responder, \% } & Tofacitinib 5 mg BID & 100.0 & 77.1 & 73.5 & 70.6 \\
\hline & Tofacitinib $10 \mathrm{mg}$ BID & 100.0 & 84.8 & 84.8 & 70.1 \\
\hline & MTX & 100.0 & 74.0 & 74.0 & 50.0 \\
\hline \multirow{3}{*}{ SDAI LDA ( $\leq 11), \%$} & Tofacitinib 5 mg BID & 78.0 & 100.0 & 94.1 & 63.1 \\
\hline & Tofacitinib $10 \mathrm{mg}$ BID & 85.2 & 100.0 & 97.8 & 71.3 \\
\hline & MTX & 69.8 & 100.0 & 96.2 & 49.1 \\
\hline \multirow[t]{3}{*}{ CDAI LDA $(\leq 10), \%$} & Tofacitinib 5 mg BID & 79.1 & 100.0 & 100.0 & 65.2 \\
\hline & Tofacitinib $10 \mathrm{mg}$ BID & 86.4 & 99.1 & 100.0 & 71.8 \\
\hline & MTX & 68.5 & 94.4 & 100.0 & 51.9 \\
\hline \multirow[t]{3}{*}{ HAQ-DI (<0.5), \% } & Tofacitinib 5 mg BID & 80.5 & 71.1 & 69.1 & 100.0 \\
\hline & Tofacitinib $10 \mathrm{mg}$ BID & 80.5 & 81.5 & 81.0 & 100.0 \\
\hline & MTX & 59.5 & 61.9 & 66.7 & 100.0 \\
\hline
\end{tabular}

ACR70 and remission clinical disease activity outcomes at month 6

\begin{tabular}{|c|c|c|c|c|c|}
\hline & & ACR70 & SDAI remission & CDAl remission & HAQ-DI $(<0.5)$ \\
\hline Overall responders, $\mathrm{n} / \mathrm{N}(\%)$ & $\begin{array}{l}\text { Tofacitinib } 5 \mathrm{mg} \text { BID } \\
\text { Tofacitinib } 10 \mathrm{mg} \text { BID } \\
\text { MTX }\end{array}$ & $\begin{array}{l}93 / 337(27.6) \\
147 / 364(40.4) \\
23 / 156(14.7) \\
\text { 2nd Outcome } \\
\end{array}$ & $\begin{array}{l}44 / 335(13.1) \\
82 / 363(22.6) \\
15 / 156(9.6)\end{array}$ & $\begin{array}{l}42 / 336(12.5) \\
77 / 363(21.2) \\
14 / 156(9.0)\end{array}$ & $\begin{array}{l}149 / 337(44.2) \\
195 / 363(53.7) \\
42 / 156(26.9)\end{array}$ \\
\hline 1st Outcome & Treatment & $\begin{array}{l}\text { ACR70 } \\
\text { responder }\end{array}$ & $\begin{array}{l}\text { SDAI remission } \\
(\leq 3.3)\end{array}$ & $\begin{array}{l}\text { CDAI remission } \\
(\leq 2.8)\end{array}$ & $\begin{array}{l}\text { HAQ-DI } \\
(<0.5)\end{array}$ \\
\hline ACR70 responder, $\%$ & $\begin{array}{l}\text { Tofacitinib } 5 \mathrm{mg} \text { BID } \\
\text { Tofacitinib } 10 \mathrm{mg} \mathrm{BID} \\
\text { MTX }\end{array}$ & $\begin{array}{l}100.0 \\
100.0 \\
100.0\end{array}$ & $\begin{array}{l}39.8 \\
51.0 \\
47.8\end{array}$ & $\begin{array}{l}37.6 \\
49.0 \\
43.5\end{array}$ & $\begin{array}{l}83.9 \\
78.2 \\
69.6\end{array}$ \\
\hline SDAI remission $(\leq 3.3), \%$ & $\begin{array}{l}\text { Tofacitinib } 5 \mathrm{mg} \text { BID } \\
\text { Tofacitinib } 10 \mathrm{mg} \text { BID } \\
\text { MTX }\end{array}$ & $\begin{array}{l}84.1 \\
91.5 \\
73.3\end{array}$ & $\begin{array}{l}100.0 \\
100.0 \\
100.0\end{array}$ & $\begin{array}{l}95.5 \\
90.2 \\
93.3\end{array}$ & $\begin{array}{l}86.4 \\
84.2 \\
73.3\end{array}$ \\
\hline CDAI remission $(\leq 2.8), \%$ & $\begin{array}{l}\text { Tofacitinib } 5 \mathrm{mg} \text { BID } \\
\text { Tofacitinib } 10 \mathrm{mg} \text { BID } \\
\text { MTX }\end{array}$ & $\begin{array}{l}83.3 \\
93.5 \\
71.4\end{array}$ & $\begin{array}{l}100.0 \\
96.1 \\
100.0\end{array}$ & $\begin{array}{l}100.0 \\
100.0 \\
100.0\end{array}$ & $\begin{array}{l}88.1 \\
83.1 \\
71.4\end{array}$ \\
\hline HAQ-DI (<0.5), \% & $\begin{array}{l}\text { Tofacitinib } 5 \mathrm{mg} \text { BID } \\
\text { Tofacitinib } 10 \mathrm{mg} \text { BID } \\
\text { MTX }\end{array}$ & $\begin{array}{l}52.4 \\
59.0 \\
38.1\end{array}$ & $\begin{array}{l}25.5 \\
35.4 \\
26.2\end{array}$ & $\begin{array}{l}24.8 \\
32.8 \\
23.8\end{array}$ & $\begin{array}{l}100.0 \\
100.0 \\
100.0\end{array}$ \\
\hline
\end{tabular}

The more similar the rates in off-diagonal cells involving the same outcome measures, the closer the concordance of the outcome measures; cells for ACR50 and CDAI LDA, and ACR70 and CDAI remission are shaded as an example.

Numbers of patients available for assessment varied between parameters; to be included, a patient must have non-missing values for both outcomes.

Response rate for the second outcome was low for ACR70 and remission outcomes (ranging from 0\% to $46 \%$ ) in patients that did not respond to the first outcome.

ACR, American College of Rheumatology; BID, twice daily; CDAI, Clinical Disease Activity Index; HAQ-DI, Health Assessment Questionnaire-Disability Index; LDA, low disease activity; MTX, methotrexate; N, number of patients assessed at month 6; n, number of responders; SDAI, Simplified Disease Activity Index.

compared with MTX (figure 4D). As expected, there was a very high concordance between SDAI and CDAI LDA and remissions (figure 4E, F). Across all analyses, discordance between clinical outcome measures was generally greater among patients treated with MTX than among those treated with tofacitinib $5 \mathrm{mg}$ (table 1; figure 4E, F).
Discordance between outcome measures was similar for tofacitinib 10 and $5 \mathrm{mg}$ (data not shown).

\section{DISCUSSION}

This analysis confirmed that a higher proportion of MTX-naive patients receiving tofacitinib 5 or $10 \mathrm{mg}$ 
Figure 2 Improvement in PROs, TJC, SJC and PGA at month 6 in patients achieving (A) ACR50,

(B) CDAI LDA and (C) HAQ-DI $<0.5$. For tofacitinib 5 and $10 \mathrm{mg}$ BID treatment groups, low levels of improvement in PROs, TJC, SJC and PGA are reported in patients who were not responsive to the first clinical outcome. ACR, American College of Rheumatology; BID, twice daily; CDAI, Clinical Disease Activity Index; HAQ-DI, Health Assessment QuestionnaireDisability Index; LDA, low disease activity; MTX, methotrexate; PGA, physician's global assessment; PROs, patientreported outcomes; PtGA, patient global assessment; SJC, swollen joint count; TJC, tender joint count.

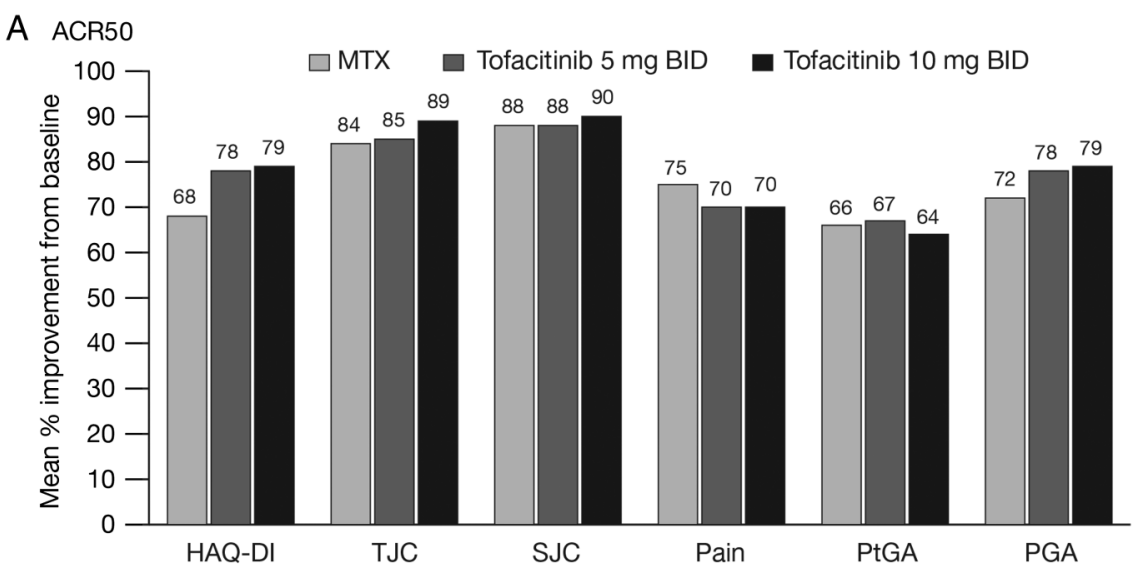

B CDAI LDA

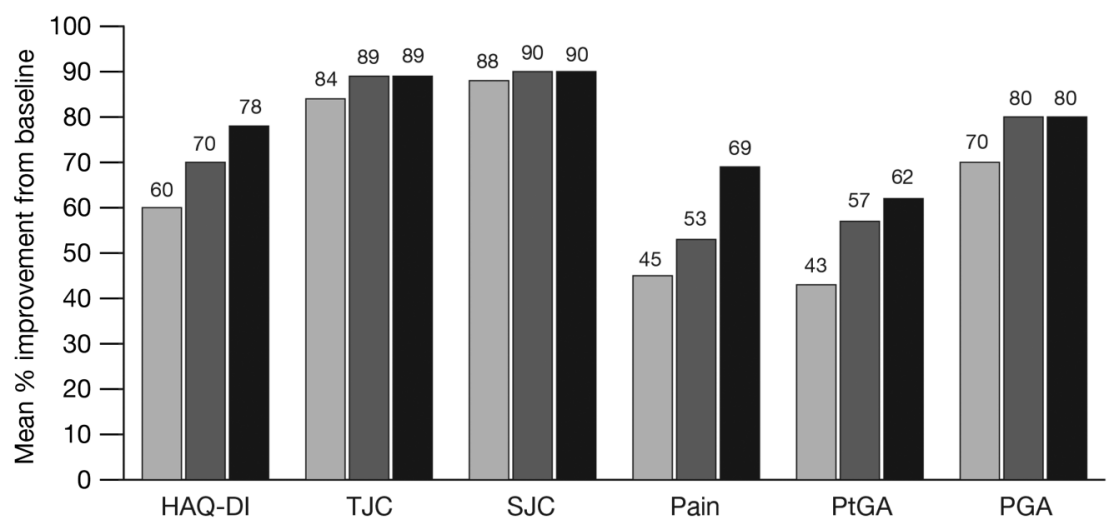

C $H A Q-D I<0.5$

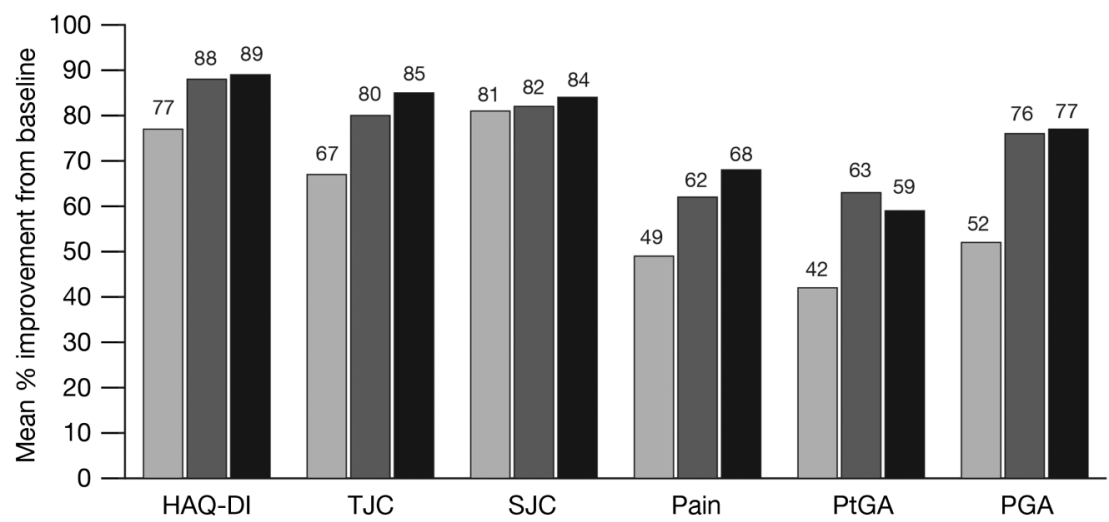

achieved clinical responses compared with patients receiving MTX. While a similar depth of improvement, whether by ACR responses, CDAI or SDAI, was reported in most patients, many achieved a response by one measure but not all.

As would be expected, ${ }^{7}$ there was a high level of agreement between rates of LDA and remission defined by SDAI and CDAI. Consistent with observations in a clinical setting, ${ }^{8}$ the level of discordance between SDAI/ CDAI and ACR responses was higher when comparing ACR70 and SDAI/CDAI remission to ACR50 and SDAI/ CDAI LDA; more patients achieve ACR70 response than achieve SDAI or CDAI remission, as these definitions of remission represent a higher threshold of response than
ACR70. Achievement of LDA by SDAI or CDAI is a lower threshold; thus, it is more likely that patients who achieve SDAI or CDAI LDA will also be ACR50 responders.

Among ACR50 responders or patients who achieved SDAI/CDAI LDA, more patients treated with tofacitinib $(63-72 \%)$ also reported improvements in physical function defined by reductions in HAQ-DI score to less than normative levels, compared with MTX-treated patients $(49-52 \%)$. Across all treatment groups, most patients (70-88\%) who achieved SDAI/CDAI remission or were ACR70 responders also reported HAQ-DI scores $<0.5$. Although patients receiving tofacitinib and MTX achieved clinically meaningful responses such as LDA or remission, the depth of response seen with 
Figure 3 Improvement in PROs, TJC, SJC and PGA at month 6 in patients achieving (A) ACR70,

(B) CDAI REM and (C) SDAI

REM. For tofacitinib 5 and $10 \mathrm{mg}$ BID treatment groups, low levels of improvement in PROs, TJC, SJC and PGA are reported in patients who were not responsive to the first clinical outcome.

ACR, American College of Rheumatology; BID, twice daily; CDAI, Clinical Disease Activity Index; HAQ-DI, Health Assessment QuestionnaireDisability Index;

MTX, methotrexate;

PGA, physician's global assessment; PROs, patientreported outcomes; PtGA, patient global assessment;

REM, remission; SDAI, Simplified Disease Activity Index;

SJC, swollen joint count;

TJC, tender joint count.

\section{A ACR70 \\ $\square$ MTX $\quad \square$ Tofacitinib 5 mg BID \\ Tofacitinib $10 \mathrm{mg}$ BID}

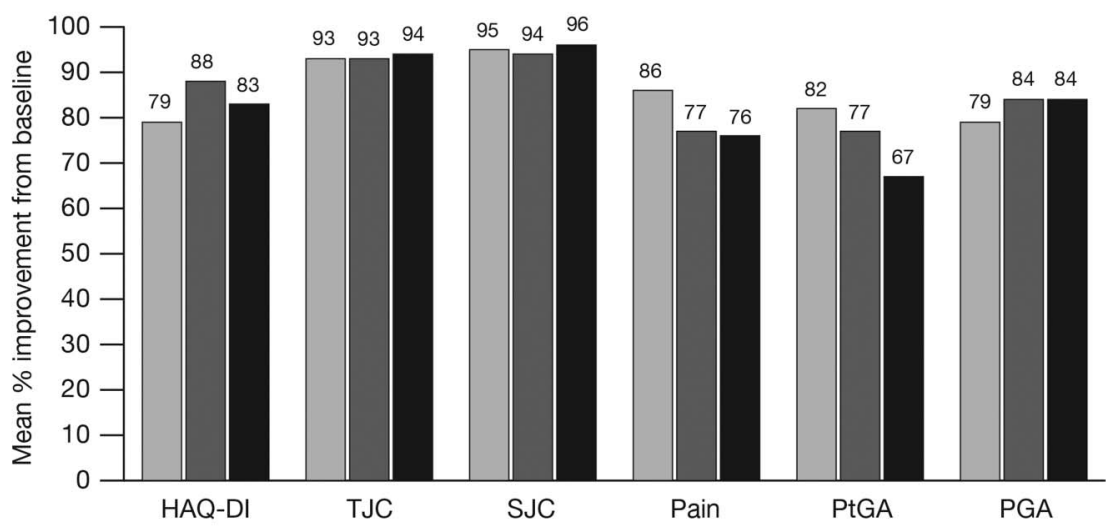

B CDAI REM

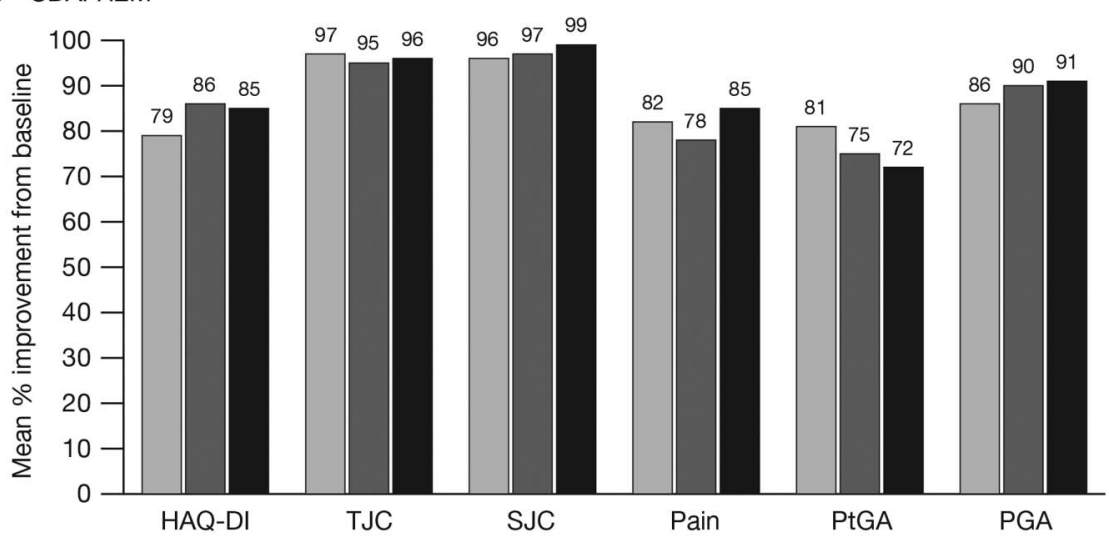

C SDAI REM

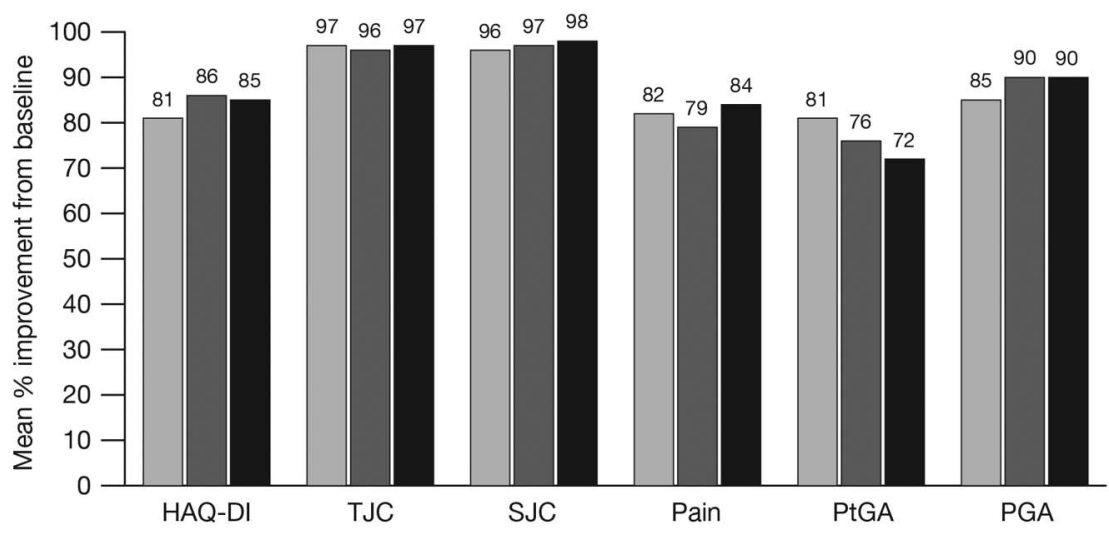

tofacitinib-treated patients was associated with quantifiably more improvements in PROs than MTX. Furthermore, although there were differences in individual efficacy responses between the two tofacitinib doses, discordance between efficacy responses was similar with tofacitinib 5 and $10 \mathrm{mg}$ twice daily.

ACR50 responders reported greater and more consistent improvements in PtGA and pain compared with those who achieved CDAI LDA or reported HAQ-DI $<0.5$. This should be expected, as ACR criteria require improvement of $\geq 20 \%, 50 \%$ or $70 \%$ in at least three of the following-PtGA, pain, HAQ-DI, PGA and an acute phase reactant (erythrocyte sedimentation rate or $\mathrm{C}$ reactive protein)— to achieve an ACR response, ${ }^{9}$ whereas
SDAI and CDAI do not include pain or HAQ-DI as part of the criteria. These results suggest that, in addition to achieving SDAI and/or CDAI LDA or remission, clinically meaningful improvements in PROs should be taken into account by the physician and patient in determining continued treatment or changes in treatment. As expected, at the higher level of ACR70 responses or the more stringent level of SDAI and/or CDAI remission, patients reported even greater improvements in PtGA and pain, which were similar across the clinical response definitions as well as between treatment groups.

Despite the overlap between these clinical measures, there is a large discordance between ACR70 and SDAI/ CDAI. ACR responses reflect a 'change' in the disease 
A
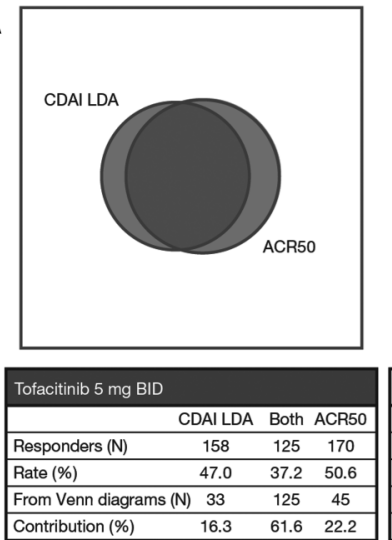

$\mathrm{B}$
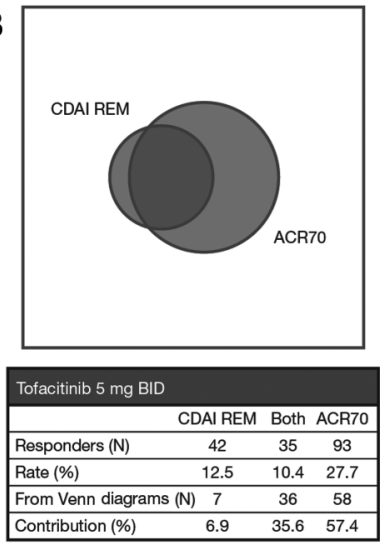

C
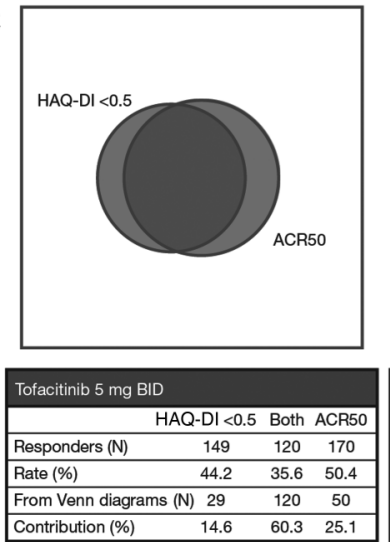
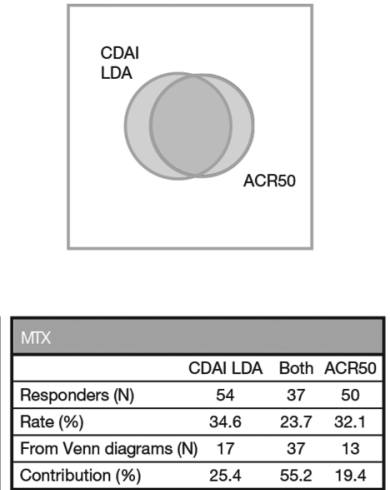

$\mathrm{D}$
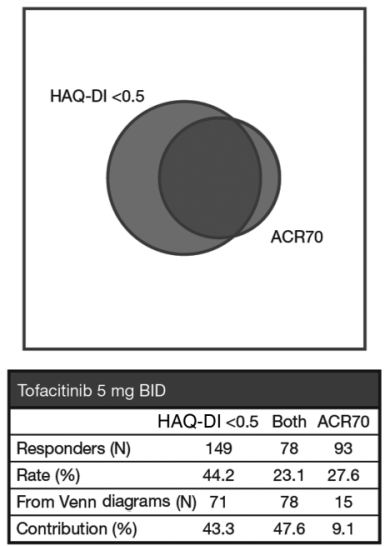

E

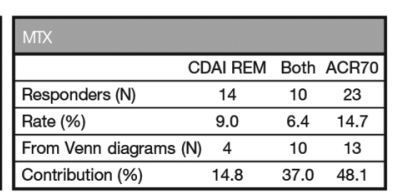

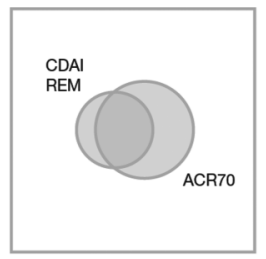
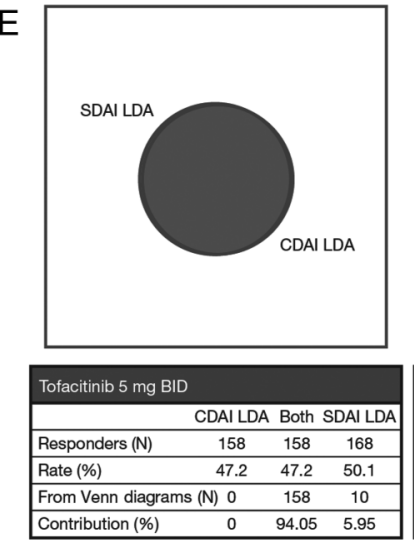

$\mathrm{F}$
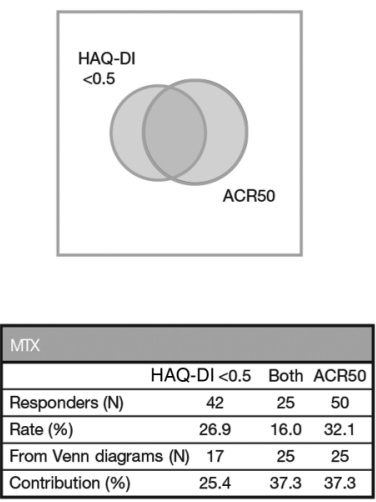
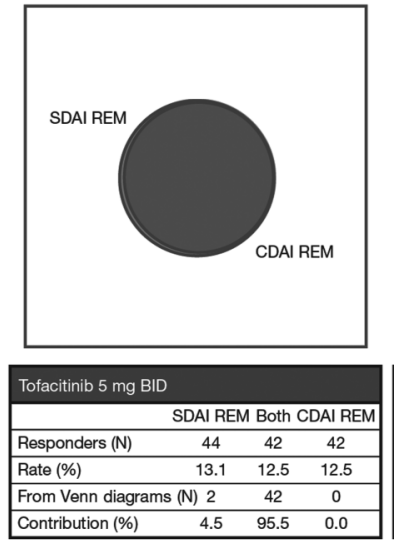
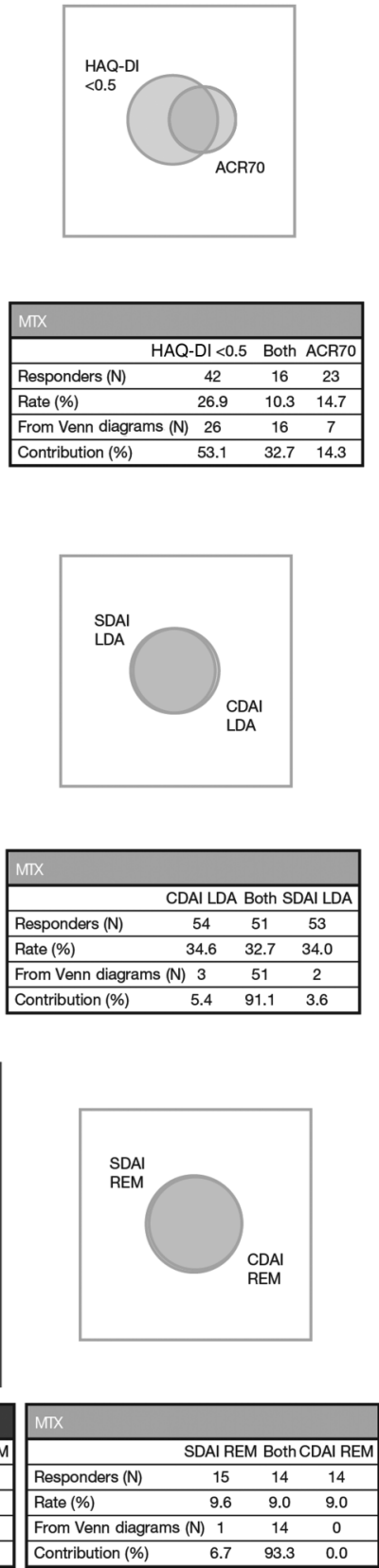

Figure 4 Venn diagram showing overlap of responses in patients treated with tofacitinib $5 \mathrm{mg}$ BID and MTX for (A) CDAI LDA and ACR50; (B) CDAI REM and ACR70; (C) HAQ-DI <0.5 and ACR50; (D) HAQ-DI <0.5 and ACR70; (E) SDAI LDA and CDAI LDA and (F) SDAI REM and CDAI REM. The more the two circles of the Venn diagram overlap, the higher the concordance. Relative sizes of the Venn diagrams for tofacitinib $5 \mathrm{mg} \mathrm{BID}$ and MTX approximately reflect the smaller sample size of the MTX group. To be included in a Venn diagram, a patient must have non-missing values for both outcomes. The rows labelled Responders $(\mathrm{N})$ represent the number of patients responsive for the first outcome, both outcomes and the second outcome, respectively. Rate (\%), represents the overall response rate to the first outcome, both outcomes and the second outcome, respectively. The rows labelled From Venn diagrams $(\mathrm{N})$ respresent the number of patients only responsive to the first outcome, both outcomes and only the second outcome, respectively; they sum to the number of patients who responded to at least one of the end points. Contribution (\%) represents the proportional size of the contribution of the total number of patients who responded to only the first outcome, both outcomes and only the second outcome, respectively. ACR, American College of Rheumatology; BID, twice daily; CDAl, Clinical Disease Activity Index; HAQ-DI, Health Assessment Questionnaire-Disability Index; LDA, low disease activity; MTX, methotrexate; REM, remission; SDAI, Simplified Disease Activity Index.

course measured between two time points, whereas SDAI and CDAI scores measure both disease 'change' and disease 'state'. Thus, patients who achieve SDAI and/or CDAI remission have minimal or no tender or swollen joints, and minimal or no disease activity assessed by the physician and patient; patients who 
achieve an ACR70 may have considerably more tender and swollen joints and disease activity, but satisfy response criteria due to sufficient change in disease activity (eg, a patient with initial SJC and TJC of 20 each and PtGA/PGA of 7 who responds to therapy and has subsequent SJC and TJC of 6 and PtGA and/or PGA of 2 has achieved an ACR70 but will have CDAI of 14, which is moderate disease activity and not LDA or remission). At the current time, SDAI or Boolean remissions are key components of the treat-to-target goals. ${ }^{10}$ HAQ-DI measures functional 'state' and functional 'change', but the goal of achieving HAQ-DI $<0.5$ is stringent, particularly for patients with long-standing disease. Improvements in PROs that are important to patients also need to be part of treatment goals. This was demonstrated by two international surveys showing that patients were reticent to discuss with their physicians persistent pain, fatigue and the effect of their disease on personal and social relationships. ${ }^{5}$ It was also illustrated in the goals patients set when initiating new therapies, often with the same desired outcome at 3 months, but with little knowledge of the term 'treat-to-target'.

As opposed to this subanalysis, which showed that clinically significant improvements in ACR70, SDAI or CDAI remission were associated with $\geq 70 \%$ of patients achieving an HAQ-DI score $<0.5$, an analysis of an observational RA cohort showed that achieving CDAI LDA or remission was associated only with modest improvements in PROs. ${ }^{11}$ In contradistinction to this observational cohort, most patients in a trial of a tumour necrosis factor inhibitor (TNFi) in MTX-inadequate responders (MTX-IR) who achieved CDAI LDA or remission also achieved 'remission' based on Routine Assessment of Patient Index Data 3 (RAPID3) scores, which is calculated from the values in the HAQ-DI of physical function, pain and PtGA. ${ }^{12}$ Another trial of TNFi in MTX-IR, utilising the same TNFi, showed moderate-to-high correlations between SDAI/CDAI and PROs: PtGA, pain, HAQ-DI and HRQoL by 36-Item Short Form Health Survey $(\mathrm{SF}-36) .{ }^{13}$

Limitations of these analyses include the lack of formal statistical testing to assess agreement between outcomes. Another limitation is that subjects randomised in this study who had not previously received MTX may not necessarily be patients with early RA, although a majority were diagnosed with disease for $<1$ year. Finally, in this study, we performed analyses based on the ACR/European League Against Rheumatism (EULAR) index-based definition of remission (SDAI $\leq 3.3$ ), but did not perform analyses using the ACR/EULAR Boolean criteria.

These analyses highlight differences in levels of response between specific PROs and clinical measures of ACR response, SDAI and CDAI at the individual patient level in MTX-naïve patients, and differences in achieving modest improvements (ACR50, SDAI and CDAI LDA) compared with significant improvements (ACR70, SDAI and CDAI remission). The goal of treatment should be to achieve clinical remission by CDAI/SDAI or ACR/ EULAR Boolean definitions and clinically meaningful improvements in PROs that are important to the individual patient, which are more likely to be achieved with a deep clinical response. This study provides insight into important correlations between attainment of clinical responses and clinically meaningful improvements in PROs, using both as tools for measuring effectiveness of treatment.

Author affiliations

${ }^{1}$ Metroplex Clinical Research Center, Dallas, Texas, USA

${ }^{2}$ Biopharmaceutical Consultant, Portola Valley, California, USA

${ }^{3}$ Pfizer Inc, Groton, Connecticut, USA

${ }^{4}$ Pfizer Inc, New York, New York, USA

${ }^{5}$ Pfizer Inc, Collegeville, Pennsylvania, USA

Acknowledgements Medical writing support was provided by Erin Bekes, $\mathrm{PhD}$, of Complete Medical Communications and was funded by Pfizer Inc. Statistical analysis support was provided by Arti Kanujia, an employee of Sciformix Corp, and Guang Ouyang, a graduate student at the University of Connecticut.

Funding The study was sponsored by Pfizer Inc.

Competing interests RF has received study grant support from Pfizer Inc and is a consultant for Pfizer Inc. VS is a consultant to AbbVie, Alder, Amgen, AstraZeneca, Biogen Idec, Biotest, BMS, Celgene, Celltrion, Corrona LLC, Crescendo, Genentech/Roche, GSK, Horizon, Hospira, Janssen, Lilly, MerckSerono, Novartis, Pfizer Inc, Protalex, Regeneron, Sanofi, Takeda, UCB and Vertex. BW, KK and EB are shareholders and employees of Pfizer Inc.

Ethics approval Institutional Review Boards (IRBs) and/or Independent Ethics Committees at each investigational centre or a central IRB.

Provenance and peer review Not commissioned; externally peer reviewed.

Data sharing statement No additional data are available.

Open Access This is an Open Access article distributed in accordance with the Creative Commons Attribution Non Commercial (CC BY-NC 4.0) license, which permits others to distribute, remix, adapt, build upon this work noncommercially, and license their derivative works on different terms, provided the original work is properly cited and the use is non-commercial. See: http:// creativecommons.org/licenses/by-nc/4.0/

\section{REFERENCES}

1. Lee EB, Fleischmann $\mathrm{R}$, Hall $\mathrm{S}$, et al. Tofacitinib versus methotrexate in rheumatoid arthritis. $N$ Engl J Med 2014;370:2377-86.

2. Strand V, Boers M, Idzerda L, et al. It's good to feel better but it's better to feel good and even better to feel good as soon as possible for as long as possible. Response criteria and the importance of change at OMERACT 10. J Rheumatol 2011;38:1720-7.

3. Pincus T, Richardson B, Strand V, et al. Relative efficiencies of the 7 rheumatoid arthritis Core Data Set measures to distinguish active from control treatments in 9 comparisons from clinical trials of 5 agents. Clin Exp Rheumatol 2014;32(Suppl 85): S47-54.

4. Michaud K, Mikuls TR, Call SE, et al. Poor to modest agreement between rheumatoid arthritis response measures in clinical practice. Clin Exp Rheumatol 2009;27:633-40.

5. Strand V, Wright GC, Bergman MJ, et al. Patient expectations and perceptions of goal-setting strategies for disease management in rheumatoid arthritis. J Rheumatol 2015;42:2046-54.

6. Arnett FC, Edworthy SM, Bloch DA, et al. The American Rheumatism Association 1987 revised criteria for the classification of rheumatoid arthritis. Arthritis Rheum 1988;31:315-24.

7. Aletaha D, Smolen JS. The Simplified Disease Activity Index (SDAI) and Clinical Disease Activity Index (CDAI) to monitor patients in standard clinical care. Best Pract Res Clin Rheumatol 2007;21:663-75. 
8. Gülfe A, Aletaha D, Saxne T, et al. Disease activity level, remission and response in established rheumatoid arthritis: performance of various criteria sets in an observational cohort, treated with anti-TNF agents. BMC Musculoskelet Disord 2009;10:41.

9. Felson DT, Anderson JJ, Boers M, et al. American College of Rheumatology. Preliminary definition of improvement in rheumatoid arthritis. Arthritis Rheum 1995;38:727-35.

10. Smolen JS, Aletaha D, Bijlsma JW, et al. Treating rheumatoid arthritis to target: recommendations of an international task force. Ann Rheum Dis 2010;69:631-7.

11. Curtis JR, Shan $\mathrm{Y}$, Harrold $\mathrm{L}$, et al. Patient perspectives on achieving treat-to-target goals: a critical examination of patient-reported outcomes. Arthritis Care Res (Hoboken) 2013;65:1707-12.

12. Pincus T, Furer V, Keystone E, et al. RAPID3 (Routine Assessment of Patient Index Data 3) severity categories and response criteria: similar results to DAS28 (Disease Activity Score) and CDAI (Clinical Disease Activity Index) in the RAPID 1 (Rheumatoid Arthritis Prevention of Structural Damage) clinical trial of certolizumab pegol. Arthritis Care Res (Hoboken) 2011;63:1142-9.

13. Strand V, Smolen JS, van Vollenhoven RF, et al. Certolizumab pego plus methotrexate provides broad relief from the burden of rheumatoid arthritis: analysis of patient-reported outcomes from the RAPID 2 trial. Ann Rheum Dis 2011;70:996-1002. 